BMJ Open Diabetes Research $\&$ Care

\section{Combination of diabetes mellitus and lack of habitual physical activity is a risk factor for functional disability in Japanese}

To cite: Fujihara K, Matsubayashi $Y$, Harada Yamada $\mathrm{M}$, et al. Combination of diabetes mellitus and lack of habitual physical activity is a risk factor for functional disability in Japanese. BMJ Open Diab Res Care 2020;8:e000901. doi:10.1136/ bmjdrc-2019-000901

- Additional material is published online only. To view please visit the journal online (http://dx.doi.org/10.1136/ bmjdrc-2019-000901).

Received 12 September 2019 Revised 2 November 2019 Accepted 11 November 2019

Check for updates

(c) Author(s) (or their employer(s)) 2020. Re-use permitted under CC BY-NC. No commercial re-use. See rights and permissions. Published by BMJ.

${ }^{1}$ Department of Endocrinology and Metabolism, Niigata University Graduate School of Medical and Dental Sciences, Niigata, Japan

${ }^{2}$ Japan Medical Data Center Co., Ltd, Tokyo, Japan

Correspondence to Dr Hirohito Sone; sone@med.niigata-u.ac.jp

\section{ABSTRACT}

Objective Declining healthy life expectancy due to functional disability is relevant and urgent because of its association with decreased quality of life and also for its enormous socioeconomic impact. The aim of this study is to examine the impact of diabetes, hypertension, dyslipidemia and physical activity habits on functional disability among community-dwelling Japanese adults. Research design and methods This is a populationbased retrospective cohort study including 9673 people aged 39-98 years in Japan (4420, men). Functional disability was defined as a condition meeting Japan's new long-term care insurance certification requirements for the need of assistance in the activities of daily living whether by caregivers or assistive devices. Cox proportionalhazards regression model identified variables related to functional disability.

Results Median follow-up was 3.7 years. During the study period, 165 disabilities occurred in the overall study population. Multivariate analysis showed that diabetes (HR $1.74(95 \% \mathrm{Cl} 1.12$ to 2.68$))$ and no physical activity habit (HR 1.83 (1.27 to 2.65)) presented increased risks for disability. HR for disability increased with the number of risk factors (HR of individuals with four conditions, 3.96 (1.59 to 9.99) vs individuals with none of those conditions as a reference). HR for disability among patients with diabetes with and without a physical activity habit was 1.68 (0.70 to 4.04) and 3.19 (1.79 to 5.70), respectively, compared with individuals without diabetes with a physical activity habit.

Conclusions The combination of diabetes and lack of habitual physical activity is predictive of functional disability in Japanese. Habitual physical activity attenuates the risk of functional disability in patients with diabetes.

\section{INTRODUCTION}

Declining healthy life expectancy due to functional disability is relevant and urgent because of its association with decreased quality of life and also for its enormous socioeconomic impact. ${ }^{12}$ Although it has been established that both chronic conditions such as diabetes, hypertension and dyslipidemia and lack of habitual physical activity are well known to

\section{Significance of this study}

What is already known about this subject?

- Diabetes and lack of habitual physical activity are well known to be associated with an increased risk of CVD and mortality.

What are the new findings?

- Diabetes and no physical activity habits can cause functional disability defined as a condition meeting Japan's new long-term care insurance certification.

How might these results change the focus of research or clinical practice?

- Habitual physical activity had a favorable influence on avoiding functional disability in patients with diabetes.

be associated with an increased risk of cardiovascular disease (CVD) and mortality, ${ }^{3-6}$ the impact of those factors and their combinations on the incidence of disability remains unclear. Therefore, we investigated the impact of those chronic conditions and physical activity habits on the occurrence of overall disability among community-dwelling Japanese adults.

\section{RESEARCH DESIGN AND METHODS \\ Study participants}

Participants in this retrospective cohort study were 11469 adults (aged 39-98 years) who had been enrolled between 1 October 2012 and 31 March 2015 and who had been followed up for at least 2 years until 31 March 2017 in Sanjyo city in Niigata prefecture. Data on 9673 people without coronary artery disease (CAD), cerebrovascular disease or functional disability at baseline and with health examination data including blood test results were analysed. However, individuals both with 
and without diabetes, hypertension and dyslipidemia at baseline were eligible for inclusion as we evaluated the relationship between new occurrence of disability and diabetes, hypertension, dyslipidemia, and physical activity.

\section{Definition of chronic conditions analysed and physical activity habits}

Participants were classified as having diabetes, hypertension and/or dyslipidemia based on HbAlc, systolic blood pressure (SBP), diastolic blood pressure (DBP), serum lipid levels and claims database data. Diabetes was defined as HbAlc $\geq 6.5 \%$ and/or the current use of antihyperglycaemic agents. Hypertension was defined as $\mathrm{SBP} \geq 140 \mathrm{~mm} \mathrm{Hg}$ and/or DBP $\geq 90 \mathrm{~mm} \mathrm{Hg}$ or the current use of antihypertensive agents. Non-HDL cholesterol (non-HDLC) was calculated based on the difference between total cholesterol and HDL-C, and dyslipidemia was defined as a non-HDLC level of $\geq 4.4 \mathrm{mmol} / \mathrm{L}$ $(170 \mathrm{mg} / \mathrm{dL})$. Presence of a physical activity habit was defined according to either a 'yes' or 'no' response to the following question: "Do you perform exercise of moderate intensity at least twice a week for 30 min over a period of 1 year?".

\section{Definition of disability}

We defined functional disability according to requirements for the new long-term care insurance (LTCI) certification. Japan implemented a mandatory social LTCI system in $2000 .^{78}$ This system automatically provides services to elderly adults (age $\geq 65$ years) and middleaged adults ( 40 to 65 years) who are certified as requiring support or care according to their needs and results of a certification assessment. Examples of conditions covered include but are not limited to cerebrovascular disease, diabetic nephropathy, diabetic retinopathy, diabetic neuropathy and so on. The selection process for classifying dependent adults first involves a questionnaire that evaluates the person's current mental and physical conditions, which is analysed using a computerised algorithm. ${ }^{7-9}$ Depending on the level of disability, services include provision of medical equipment, home visits and home care, intensive home nursing care, facility-based services and facility-based rehabilitation. A long-time care approval board makes a final decision on the care provided based on the algorithm-aided analysis of the questionnaire, a doctors' recommendation and a home visit report. Levels of disabilities designated by the LTCI programme in Japan are shown in online supplementary table 1.

\section{Statistical analysis}

Categorical variables were expressed as numerals and percentages. Continuous variables were expressed as the mean \pm SD. For comparison between the cases and non-cases groups, $\chi^{2}$ tests were used for the categorical variables. Unpaired Student's t-test was used for the continuous variables. Cox regression model identified variables related to the incidence of functional disability. Covariates included traditional risk factors for functional disability in each model: age, sex, body mass index (BMI) category, diabetes, hypertension, dyslipidemia, physical activity habits and smoking status. Unadjusted overall time to development of a functional disability was derived by a cumulative incidences rate curve and log-rank tests. Analyses were performed using SPSS V.19.0. Statistical significance was considered for $p$ values $<0.05$.

\section{RESULTS}

Median follow-up was 3.7 years. During the study period, 165 study participants developed new functional disabilities. The number of individuals requiring various levels of support and care under the LTCI programme is shown in online supplementary table 2. 'Support' refers to home-based services such as for cooking, shopping, eating and bathing as well as facility-based services such as adult day care. 'Care' refers to home-based medically oriented assistance principally provided by nurses and facility-based care such as outpatient rehabilitation as well as short-term and long-term care. The incidence rate of functional disabilities was 4.65 per 1000 personyears. Baseline characteristics of those who had or had not experienced disability during the observational period are summarized in table 1 . Individuals with functional disabilities were significantly older and had a higher prevalence of diabetes, hypertension and lack of a physical activity habit compared with those without these factors whereas those without functional disabilities had lower levels of total cholesterol and non-HDLC (table 1). Multivariate analysis showed that diabetes (HR 1.74 (95\% CI 1.12 to 2.68$)$ ), no physical activity habit (HR 1.83 (1.27 to 2.65)) and low BMI category (18.5 kg/ $\mathrm{m}^{2}>$ ) (HR 1.63 (1.02 to 2.63)) presented increased risks for disability (table 2). Online supplementary table 3 shows the association between functional disability risk and the number of factors present among diabetes, hypertension, dyslipidemia and no physical activity habit. The prevalence ratio of $0,1,2,3$ and 4 conditions was $12.8 \%, 40.0 \%, 32.6 \%, 12.9 \%$ and $1.7 \%$, respectively. Risk for functional disability increased with the number of those conditions present compared with none of those conditions (online supplementary table 3). The risks for functional disability increased in individuals with diabetes who had no habitual physical activity, whereas those relationships were attenuated in individuals with diabetes who undertook habitual physical activity (table 3). Cumulative incidence rates for functional disability in each group are shown in figure 1 . The incidences of functional disability in those with diabetes, hypertension and no habitual physical activity were significantly higher than in those without (all $\mathrm{p}<0.01)$ whereas those relationships were not observed with regard to dyslipidemia $(\mathrm{p}=0.647)$. 
Table 1 Characteristics of study participants according to the presence or absence of disability

\begin{tabular}{|c|c|c|c|}
\hline \multirow[b]{3}{*}{ Characteristic } & \multicolumn{2}{|l|}{ Disability } & \multirow[b]{3}{*}{$P$ value } \\
\hline & $(-)$ & $(+)$ & \\
\hline & $(n=9508)$ & $(n=165)$ & \\
\hline Male sex (\%) & $4335(46)$ & $85(52)$ & 0.130 \\
\hline Age (years) & $65 \pm 9$ & $78 \pm 8$ & $<0.001$ \\
\hline $\begin{array}{l}\text { Body mass index } \\
\left(\mathrm{kg} / \mathrm{m}^{2}\right)\end{array}$ & $22.6 \pm 3.1$ & $22.2 \pm 3.2$ & 0.058 \\
\hline$<18.5$ & $732(8)$ & $21(13)$ & \\
\hline $18.5-25.0$ & $6845(72)$ & $114(69)$ & \\
\hline$\geq 25.0$ & $1931(20)$ & $30(18)$ & \\
\hline $\begin{array}{l}\text { Systolic blood } \\
\text { pressure }(\mathrm{mm} \mathrm{Hg})\end{array}$ & $127 \pm 17$ & $132 \pm 18$ & $<0.001$ \\
\hline $\begin{array}{l}\text { Diastolic blood } \\
\text { pressure }(\mathrm{mm} \mathrm{Hg})\end{array}$ & $75 \pm 11$ & $73 \pm 11$ & 0.120 \\
\hline HbA1c (\%) & $5.7 \pm 0.6$ & $5.7 \pm 0.6$ & 0.168 \\
\hline $\mathrm{HbA1c}(\mathrm{mmol} / \mathrm{mol})$ & $39 \pm 6$ & $39 \pm 7$ & \\
\hline $\begin{array}{l}\text { Total cholesterol } \\
(\mathrm{mmol} / \mathrm{L})\end{array}$ & $5.2 \pm 0.8$ & $5.0 \pm 0.9$ & 0.001 \\
\hline $\begin{array}{l}\text { HDL cholesterol } \\
(\mathrm{mmol} / \mathrm{L})\end{array}$ & $1.6 \pm 0.4$ & $1.5 \pm 0.4$ & 0.130 \\
\hline $\begin{array}{l}\text { Non-HDL } \\
\text { cholesterol } \\
\text { (mmol/L) }\end{array}$ & $3.7 \pm 0.8$ & $3.5 \pm 0.8$ & 0.009 \\
\hline Diabetes (\%) & $767(8.1)$ & $25(15)$ & 0.001 \\
\hline Hypertension (\%) & 3938 (41) & $96(58)$ & $<0.001$ \\
\hline Dyslipidemia (\%) & $3343(35)$ & $55(33)$ & 0.626 \\
\hline $\begin{array}{l}\text { Physical activity } \\
\text { habits (\%) }\end{array}$ & 3294 (35) & $38(23)$ & 0.002 \\
\hline $\begin{array}{l}\text { Current smoking } \\
(\%)\end{array}$ & $1323(14)$ & $15(9)$ & 0.075 \\
\hline
\end{tabular}

Data are presented as numbers, means \pm SDs or percentages. HDL, high-density lipoprotein.

Table 2 Cox regression analysis of variables for the incidence of functional disability

\begin{tabular}{|c|c|c|}
\hline & HR (95\% Cl) & $P$ value \\
\hline Age, 5-year increase & 2.48 (2.23 to 2.75$)$ & $<0.001$ \\
\hline Male sex & 1.25 (0.90 to 1.74$)$ & 0.178 \\
\hline \multicolumn{3}{|l|}{ Body mass index } \\
\hline$<18.5$ & 1.63 (1.02 to 2.63$)$ & 0.043 \\
\hline $18.5-24.9$ & Ref & \\
\hline$\geq 25.0$ & 1.01 (0.67 to 1.52$)$ & 0.962 \\
\hline Diabetes & 1.74 (1.12 to 2.68$)$ & 0.013 \\
\hline Hypertension & 1.23 (0.89 to 1.70$)$ & 0.208 \\
\hline Dyslipidemia & $1.00(0.71$ to 1.41$)$ & 0.997 \\
\hline No physical activity habit & 1.83 (1.27 to 2.65$)$ & 0.001 \\
\hline Current smoking & 1.35 (0.77 to 2.38$)$ & 0.293 \\
\hline
\end{tabular}

\section{CONCLUSIONS}

This is the first study to examine the impact of chronic conditions and physical activity habits alone or in combination on the development of overall disability in Japanese. The present results showed the association of diabetes and no physical activity habits with functional disability. In addition, it was indicated that habitual physical activity attenuates the risk of functional disability in patients with diabetes. Diabetes has been closely linked to the risk of physical disability, ${ }^{10}$ visual impairment, ${ }^{11}$ cancer, ${ }^{12}$ frailty, ${ }^{13}$ fractures ${ }^{14}$ dementia ${ }^{15}$ and cardiovascular disease ${ }^{3}$; thus, the risk for overall disability is greater in those with diabetes compared with those without diabetes. Similarly, low physical activity was associated with those diseases based on frailty. ${ }^{16}{ }^{17}$ However, we noted that the risk for functional disability was lower in individuals with diabetes who engaged in habitual physical activity. Because the presence of diabetes may not be a modifiable condition, it would be important to focus on modifiable factors such as physical activity habits that could attenuate the association of diabetes with functional disability.

We found that the presence of hypertension was associated with a higher risk for functional disabilities compared with the absence of hypertension (figure 1). Hypertension has been associated with a significantly increased risk of CVD and dementia. ${ }^{418}$ Although a high level of non-HDLC is an established risk factor for CAD and CVD, ${ }^{19}$ statin treatment was not associated with a reduction in atherosclerotic CVD or in all-cause mortality in primary prevention in older adults without diabetes. ${ }^{20}$ Moreover, the impact of blood pressure was shown to be greater on cerebrovascular disease than serum lipids. ${ }^{21} 22$ In general, cerebrovascular disease tended to be associated with prolonged need for assistance in the activities of daily living compared with CAD due to motor paralysis or dysphagia.

Multivariate analyses showed that HRs for functional disability increased with the number of risk factors using no risk factor as the reference. Those findings suggested that individuals with two or more of those conditions indicating risk should be screened and interventions such as medical treatments and lifestyle management, including nutrition education, resistance training and aerobic exercise, should be applied for the prevention of functional disabilities.

Lower BMI $(<18.5)$ was independently associated with functional disability. Those results were consistent with previous studies, ${ }^{23}{ }^{24}$ suggesting that lower BMI in part reflects loss of lean mass. Exercise and nutritional interventions were shown to improve muscle strength and physical function significantly. ${ }^{25}{ }^{26}$ Physical exercise was noted to be effective in preventing the progression of frailty and further disability in older Japanese adults. ${ }^{27}$ Taken together, clinicians may need to consider those with lower BMI as being at high risk for functional 
Table 3 HRs with 95\% Cls according to risk of diabetes, no habitual physical activity and their combination for disability analysed by Cox models

\begin{tabular}{lclc}
\hline & Cases/total $\mathbf{n}$ & HR (95\% Cl) & P value \\
\hline Diabetes (-) Physical activity habits (+) & $32 / 3014$ & 1.00 (ref) & \\
Diabetes (-) Physical activity habits (-) & $108 / 5867$ & $1.82(1.22$ to 2.71$)$ & 0.003 \\
Diabetes (+) Physical activity habits (+) & $6 / 320$ & $1.68(0.70$ to 4.04$)$ & 0.244 \\
Diabetes (+) Physical activity habits (-) & $19 / 472$ & $3.20(1.79$ to 5.70$)$ & $<0.001$ \\
\hline
\end{tabular}

Adjusted for age, sex, body mass index, hypertension, dyslipidemia, current smoking.

disability and examine these patients for the presence of frailty.

This study's strengths were the large sample size and accurate definitions of diabetes, hypertension, dyslipidemia and disability using data from health examinations and a claims and administrative database. These sources allowed us to precisely identify almost all patients with those conditions during follow-up. This study has some limitations. First, the design was retrospective, and only participants who underwent physical examinations with blood tests were analysed. Moreover, there was no way to identify those participants whose glucose tolerance status, blood pressure, physical activity and lipids either improved or deteriorated during follow-up, which lasted a minimum of 2 years. Second, we could not assess in detail why the patients needed LTCI services. Thus, further detailed investigations would be needed that use data on the main cause for needing LTCI services, such as those on social relationships and socioeconomic status such as employment status and/or income. Third,
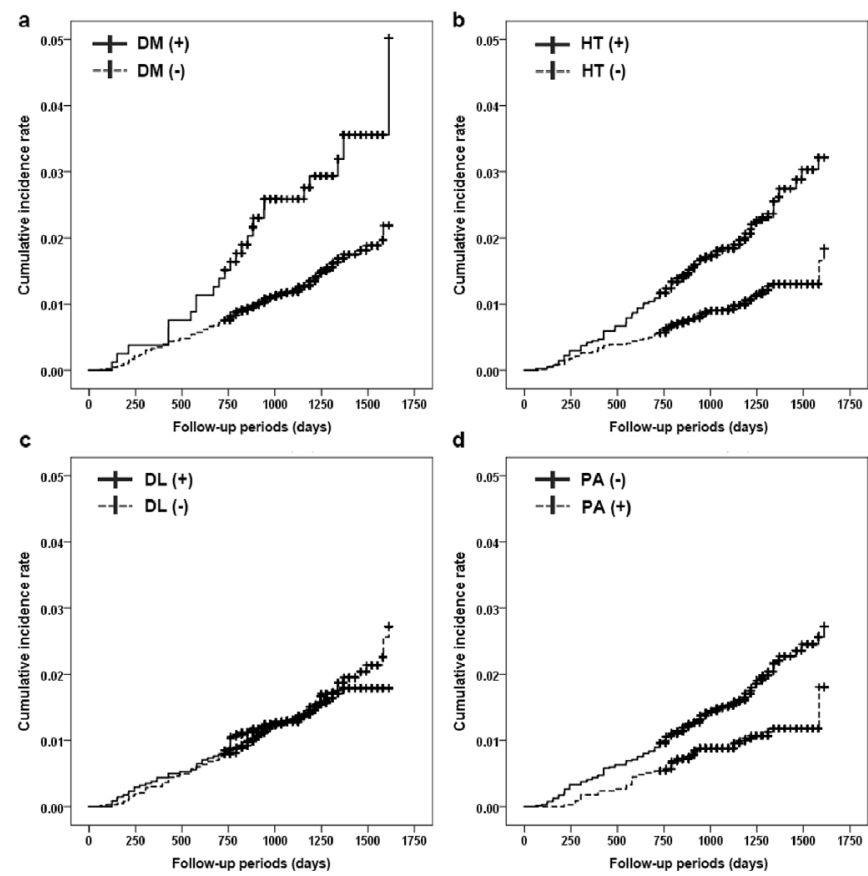

Figure 1 Cumulative incidence rates of disability according to various risk factors (a) diabetes mellitus, (b) hypertension, (c) high non-HDLC level and (d) no habitual physical activity. DL, dyslipidemia; DM, diabetes mellitus; HT, hypertension; PA, physical activity habit. physical activity habits were measured using a simple oneitem questionnaire rather than more precise measurements such as with an acceleration sensor, which may have introduced measurement error. Moreover, we did not have detailed data on the means of physical activity such as aerobic, balance and resistance training. Fourth, we could not ascertain the duration of diabetes and distinguish between individuals with type 1 and type 2 diabetes. However, type 2 diabetes is more common than type 1 diabetes and accounts for $95 \%$ of diabetes in Japan. Finally, we did not have data on anthropometric measurements, dietary patterns, mental health, socioeconomic status and social frailty such as living alone, going out infrequently and having friends. ${ }^{28-30}$ Thus, future studies are necessary to confirm our findings considering these important factors.

In summary, diabetes and no habitual physical activity were shown to be independent risk factors for overall disability in Japanese. Habitual physical activity had a favorable influence on avoiding functional disability in patients with diabetes.

Acknowledgements The authors also thank Mami Haga and Noriko Hasegawa, Niigata University Faculty of Medicine, for excellent secretarial assistance.

Contributors KF developed the study design, researched the data, contributed to discussions, wrote the manuscript, and reviewed and edited the manuscript. TY, AT and YM planned and supervised this research, researched the data, contributed to discussions, wrote the manuscript, and reviewed and edited the manuscript. YM, MY, MKi, MHY, MKa and SK researched the data, contributed to discussions, wrote the manuscript, and reviewed and edited the manuscript. KK researched the data and reviewed and edited the manuscript. HS developed the study design, contributed to discussions, and reviewed and edited the manuscript.

Funding This work is supported in part by the Japan Society for the Promotion of Science.

Competing interests None declared.

Patient consent for publication Not required.

Ethics approval The Ethics Committee of the Niigata University approved this study (2015-2355).

Provenance and peer review Not commissioned; externally peer reviewed.

Data availability statement № data are available.

Open access This is an open access article distributed in accordance with the Creative Commons Attribution Non Commercial (CC BY-NC 4.0) license, which permits others to distribute, remix, adapt, build upon this work non-commercially, and license their derivative works on different terms, provided the original work is properly cited, appropriate credit is given, any changes made indicated, and the use is non-commercial. See: http://creativecommons.org/licenses/by-nc/4.0/.

ORCID iD

Hirohito Sone http://orcid.org/0000-0003-1263-2817 


\section{REFERENCES}

1 Murray CJL, Barber RM, Foreman KJ, et al. Global, regional, and national disability-adjusted life years (DALYs) for 306 diseases and injuries and healthy life expectancy (HALE) for 188 countries, 1990-2013: quantifying the epidemiological transition. Lancet 2015;386:2145-91.

2 WHO. World report on disability. Geneva: World Health Organization, 2011.

3 Fox CS, Coady S, Sorlie PD, et al. Trends in cardiovascular complications of diabetes. JAMA 2004;292:2495-9.

4 Kannel WB. Blood pressure as a cardiovascular risk factor: prevention and treatment. JAMA 1996;275:1571-6.

5 Castelli WP. Lipids, risk factors and ischaemic heart disease. Atherosclerosis 1996;124 Suppl:S1-9.

6 Shiroma EJ, Lee IM. Physical activity and cardiovascular health: lessons learned from epidemiological studies across age, gender, and race/ethnicity. Circulation 2010;122:743-52.

7 Tsutsui T, Muramatsu N. Care-needs certification in the long-term care insurance system of Japan. J Am Geriatr Soc 2005;53:522-7.

8 Tsutsui T, Muramatsu N. Japan's universal long-term care system reform of 2005: containing costs and realizing a vision. J Am Geriatr Soc 2007;55:1458-63.

9 Kondo N, Suzuki K, Minai J, et al. Positive and negative effects of finance-based social capital on incident functional disability and mortality: an 8-year prospective study of elderly Japanese. $J$ Epidemiol 2012;22:543-50.

10 Wong E, Backholer K, Gearon E, et al. Diabetes and risk of physical disability in adults: a systematic review and meta-analysis. Lancet Diabetes Endocrinol 2013;1:106-14.

11 Leasher JL, Bourne RRA, Flaxman SR, et al. Global estimates on the number of people blind or visually impaired by diabetic retinopathy: a meta-analysis from 1990 to 2010. Diabetes Care 2016;39:1643-9.

12 Noto H, Osame K, Sasazuki T, et al. Substantially increased risk of cancer in patients with diabetes mellitus: a systematic review and meta-analysis of epidemiologic evidence in Japan. $J$ Diabetes Complications 2010;24:345-53.

13 Li G, Prior JC, Leslie WD, et al. Frailty and risk of fractures in patients with type 2 diabetes. Diabetes Care 2019;42:507-13.

14 Gilbert MP, Pratley RE. The impact of diabetes and diabetes medications on bone health. Endocr Rev 2015;36:194-213.

15 Biessels GJ, Staekenborg S, Brunner E, et al. Risk of dementia in diabetes mellitus: a systematic review. Lancet Neurol 2006;5:64-74.

16 Huisingh-Scheetz M, Wroblewski K, Kocherginsky M, et al. The relationship between physical activity and frailty among U.S. older adults based on hourly accelerometry data. J Gerontol A Biol Sci Med Sci 2018;73:622-9.
17 Peterson MJ, Giuliani C, Morey MC, et al. Physical activity as a preventative factor for frailty: the health, aging, and body composition study. J Gerontol A Biol Sci Med Sci 2009;64A:61-8.

18 Kennelly SP, Lawlor BA, Kenny RA. Review: blood pressure and dementia - a comprehensive review. Ther Adv Neurol Disord 2009;2:241-60.

19 Cui Y, Blumenthal RS, Flaws JA, et al. Non-high-density lipoprotein cholesterol level as a predictor of cardiovascular disease mortality. Arch Intern Med 2001;161:1413-9.

20 Ramos R, Comas-Cufí M, Martí-Lluch R, et al. Statins for primary prevention of cardiovascular events and mortality in old and very old adults with and without type 2 diabetes: retrospective cohort study. BMJ 2018;362.

21 Anon. Blood pressure, cholesterol, and stroke in eastern Asia. Eastern Stroke and Coronary Heart Disease Collaborative Research Group. Lancet 1998;352:1801-7.

22 Asia Pacific Cohort Studies Collaboration. Joint effects of systolic blood pressure and serum cholesterol on cardiovascular disease in the Asia Pacific region. Circulation 2005;112:3384-90.

23 Yamada M, Arai H, Nishiguchi S, et al. Chronic kidney disease (CKD) is an independent risk factor for long-term care insurance (LTCI) need certification among older Japanese adults: a two-year prospective cohort study. Arch Gerontol Geriatr 2013;57:328-32.

24 Tomata Y, Hozawa A, Ohmori-Matsuda K, et al. [Validation of the Kihon Checklist for predicting the risk of 1-year incident long-term care insurance certification: the Ohsaki Cohort 2006 Study]. Nihon Koshu Eisei Zasshi 2011;58:3-13.

25 Theodorakopoulos $\mathrm{C}$, Jones J, Bannerman E, et al. Effectiveness of nutritional and exercise interventions to improve body composition and muscle strength or function in sarcopenic obese older adults: a systematic review. Nutr Res 2017;43:3-15.

26 Liu C-J, Latham NK. Progressive resistance strength training for improving physical function in older adults. Cochrane Database Syst Rev 2009:CD002759.

27 Yamada M, Arai H, Sonoda T, et al. Community-based exercise program is cost-effective by preventing care and disability in Japanese frail older adults. J Am Med Dir Assoc 2012;13:507-11.

28 Castora-Binkley M, Meng H, Hyer K. Predictors of long-term nursing home placement under competing risk: evidence from the health and retirement study. J Am Geriatr Soc 2014;62:913-8.

29 Tomata Y, Watanabe T, Sugawara Y, et al. Dietary patterns and incident functional disability in elderly Japanese: the Ohsaki cohort 2006 study. J Gerontol A Biol Sci Med Sci 2014;69:843-51.

30 Makizako H, Shimada $\mathrm{H}$, Tsutsumimoto $\mathrm{K}$, et al. Social frailty in community-dwelling older adults as a risk factor for disability. J Am Med Dir Assoc 2015;16:1003.e7-11. 